\title{
Role for inducible cAMP early repressor in promoting pancreatic beta cell dysfunction evoked by oxidative stress in human and rat islets
}

\author{
D. Favre • G. Niederhauser • D. Fahmi • V. Plaisance • \\ S. Brajkovic • N. Beeler • F. Allagnat • J. A. Haefliger • \\ R. Regazzi • G. Waeber $\cdot$ A. Abderrahmani
}

Received: 15 November 2010 / Accepted: 1 April 2011 /Published online: 6 May 2011

(C) The Author(s) 2011. This article is published with open access at Springerlink.com

\begin{abstract}
Aims/hypothesis Pro-atherogenic and pro-oxidant, oxidised LDL trigger adverse effects on pancreatic beta cells, possibly contributing to diabetes progression. Because oxidised LDL diminish the expression of genes regulated by the inducible cAMP early repressor (ICER), we investigated the involvement of this transcription factor and of oxidative stress in beta cell failure elicited by oxidised LDL.

Methods Isolated human and rat islets, and insulinsecreting cells were cultured with human native or oxidised LDL or with hydrogen peroxide. The expression of genes was determined by quantitative real-time PCR and western blotting. Insulin secretion was monitored by EIA kit. Cell apoptosis was determined by scoring cells displaying pycnotic nuclei.
\end{abstract}

Electronic supplementary material The online version of this article (doi:10.1007/s00125-011-2165-x) contains supplementary material, which is available to authorised users.

D. Favre $\cdot$ G. Niederhauser $\cdot$ D. Fahmi $\cdot$ V. Plaisance $\cdot$

S. Brajkovic $\cdot$ N. Beeler · F. Allagnat · J. A. Haefliger $\cdot$

G. Waeber $\cdot$ A. Abderrahmani $(\square)$

Service of Internal Medicine, CHUV-Hospital,

Lausanne, Switzerland

e-mail: Amar.Abderrahmani@unil.ch

D. Favre $\cdot$ G. Niederhauser $\cdot$ D. Fahmi $\cdot$ V. Plaisance $\cdot$

S. Brajkovic $\cdot$ N. Beeler $\cdot$ R. Regazzi $\cdot$ A. Abderrahmani

Department of Cell Biology and Morphology,

University of Lausanne,

Rue du Bugnon 9,

1005 Lausanne, Switzerland

A. Abderrahmani

CNRS-UMR-8199, Université Lille Nord de France,

UDSL, Lille, France
Results Exposure of beta cell lines and islets to oxidised LDL, but not to native LDL raised the abundance of ICER. Induction of this repressor by the modified LDL compromised the expression of important beta cell genes, including insulin and anti-apoptotic islet brain 1 , as well as of genes coding for key components of the secretory machinery. This led to hampering of insulin production and secretion, and of cell survival. Silencing of this transcription factor by RNA interference restored the expression of its target genes and alleviated beta cell dysfunction and death triggered by oxidised LDL. Induction of ICER was stimulated by oxidative stress, whereas antioxidant treatment with $N$-acetylcysteine or HDL prevented the rise of ICER elicited by oxidised LDL and restored beta cell functions.

Conclusions/interpretation Induction of ICER links oxidative stress to beta cell failure caused by oxidised LDL and can be effectively abrogated by antioxidant treatment.

Keywords Antioxidant - Apoptosis · Diabetes · HDL · ICER · Insulin · Oxidative stress · Oxidised LDL ·

Pancreatic beta cells
Abbreviations
CRE cAMP responsive elements
CREluc Luciferase reporter construct driven by two CRE sequences linked upstream to a SV40 promoter
hGH Human growth hormone
ICER Inducible cAMP early repressor
JNK c-Jun amino terminal kinase
MAPK Mitogen-activated protein kinase
NAC $N$-Acetylcysteine
ROS Reactive oxygen species
si Small interfering 


\section{Introduction}

A decline in the number of insulin-producing beta cells and/or their intrinsic ability to produce and/or secrete insulin contributes to the pathophysiology of type 2 diabetes [1]. Chronic excess of cholesterol and metabolic fuels, such as the NEFA palmitate and glucose, conspire with genetic factors to trigger beta cell dysfunction and destruction over time [2-6]. Low plasma levels of HDL together with increased levels of oxidised LDL-cholesterol are associated with diabetes, thereby elevating risk of developing atherosclerosis and ultimately cardiovascular diseases [7, 8]. The fact that perturbations of these lipoproteins precede development of diabetes has led to the hypothesis that they could contribute to the progression of the disease [9-12]. So far, numerous clues support a role for oxidised LDL in triggering adverse effects in beta cells and thereby contributing to the pathophysiology of diabetes. Prolonged exposure of insulin-producing cell lines, as well as isolated human and rodents islets to oxidised LDL at physiological cholesterol concentration compromised insulin production and secretion, and increased the rates of apoptosis [6, 13-15], while native LDL at a similar cholesterol concentration did not exert such adverse effects. Coincubation of cells with HDL permitted abrogation of the harmful effects of oxidised LDL [13]. Positive effects, as well as protective properties of this particle against toxicity generated by chronic hyperglycaemia have also been shown $[15,16]$, validating the concept that adequate levels of HDL are required for beta cell function and control of glucose homeostasis.

A wealth of data point to oxidative stress as the link coupling oxidised LDL to cell dysfunction and death $[17,18]$. The hypothesis that oxidative stress can mediate beta cell dysfunction caused by proatherogenic oxidised LDL is further supported by a clinical trial investigating the efficiency of an antioxidant in cardiovascular events in patients with acute coronary diseases [19]. Daily administration of the antioxidant molecule markedly reduced the occurrence of new-onset diabetes [19]. Furthermore, in vitro induction of specific signalling cascades supports involvement of oxidative stress in beta cell failure evoked by oxidised LDL. Activation of the mitogen-activated protein kinase (MAPK) pathways, including MAPK8 (also called c-Jun amino terminal kinase [JNK]), is one of the hallmarks of oxidative stress $[20,21]$. Activation of JNK signalling in beta cells leads to programmed cell death and impaired insulin expression [20,21]. Induction of JNK activity has been demonstrated to contribute to beta cell dysfunction caused by oxidised LDL [13].
Increased JNK activity caused by oxidised LDL results from reduced levels of MAPK8 interacting protein-1 (also called JNK interacting protein 1 or islet brain 1), a potent inhibitor of JNK activity in beta cells $[13,22]$. Islet brain 1 is a target of the inducible cAMP early repressor (ICER), a member of the cAMP responsive element (CRE) modulator transcription factors [23]. ICER is a powerful passive repressor, which silences expression of genes that contain a CRE within their promoters [24]. Induction of ICER is in part responsible for beta cell failure evoked by hyperglycaemia and fatty acids $[25,26]$. This negative role is achieved by silencing expression of insulin [27] and components of the secretory machinery, such as the GTPases Rab3a and Rab27a, and their effectors Slp4 (also known as Sytl4) and Noc2 (also known as Rph3al) [25]. All these observations led us to investigate whether oxidised LDL may trigger beta cell failure by inducing production of ICER in a mechanism that involves oxidative stress.

\section{Methods}

Lipoprotein preparation Blood was collected from healthy donors. Plasma LDL fractions were isolated by sequential ultracentrifugation (LDL density 1.063) exactly as described [13]. Oxidation of LDL particles was done by incubating $1 \mathrm{mg} \mathrm{LDL}$ protein/ml PBS with $5 \mu \mathrm{mol} / 1 \mathrm{CuSO} 4$ at $37^{\circ} \mathrm{C}$ for $6-8 \mathrm{~h}$ [13]. The oxidation reaction was verified as previously described by determining the lipid peroxide content [13].

Cell culture and preparation of isolated islets The insulinsecreting cell line (MIN6) was maintained as previously described [13]. Isolated human islets were obtained from the Cell Isolation and Transplantation Center (islets for research distribution programme) of the Geneva University Hospital (Geneva, Switzerland). Investigations were been approved by the responsible ethics committee. Islets were cultured in CMRL-1066 supplemented with 10\% (vol./vol.) fetal bovine serum (Mediatech, Herndon, VA, USA) in 5\% $\mathrm{CO}_{2}$ humidified atmosphere at $37^{\circ} \mathrm{C}$. Rat islets were isolated from the pancreas of male Sprague-Dawley rats weighing $250-350 \mathrm{~g}$ by ductal injection of collagenase $\mathrm{P}$ (Roche Diagnostics, Rotkreuz, Switzerland). Purification and culture of islets was conducted as described [13]. Experimental protocols were approved by the Cantonal Veterinary Office.

Small interfering RNA and transfection A pool of two 19nucleotide pre-validated small interfering (si) RNA duplexes that target the mouse and rat Icer (also known as Crem) 
sequence (si-Icer) were chemically synthesised by Mycrosynth (Balgach, Switzerland). The two target sequences of Icer were: 5'-CTGGAGATGAAACTGCTGC-3' and 5'CTGGAGATGAAACTGATGA-3'. Transient transfection experiments were performed using a kit (Lipofectamine 2000 transfection; Invitrogen, Basel, Switzerland) as reported [23].

Measurement of secretion Cells $\left(5 \times 10^{5}\right)$ were plated in 24well dishes and cultured in the presence of vehicle, native and oxidised LDL for $72 \mathrm{~h}$. When human growth hormone (hGH) was used as a reporter for regulated secretion, the cells were first transiently transfected with a construct encoding the hGH and $24 \mathrm{~h}$ later cultured with lipoproteins for $72 \mathrm{~h}$. Thereafter, the cells were washed three times with modified KRB HEPES buffer (10 mmol/1 HEPES, 0.1\% [wt/vol.] bovine serum albumin) containing insulin secretagogues $(20 \mathrm{mmol} / 1$ of glucose or $30 \mathrm{mmol} / \mathrm{K} \mathrm{KCl})$. Insulin released in the supernatant fraction and insulin cellular contents were measured by EIA (Cayman Chemical, Ann Arbor, MI, USA) as recommended by the manufacturer's protocol. Exocytosis from transfected cells was assessed by ELISA (Roche Diagnostics, Rotkreuz, Switzerland) that measured the amount of hGH released into the medium during the incubation period.

Apoptosis assay Apoptosis was determined by scoring cells displaying pycnotic nuclei (visualised with Hoechst 33342) [13]. The counting was performed blind by three different experimenters.

Measurement of superoxide After treatment, MIN6 cells were washed twice with PBS $1 \times$ and scraped in PBS $1 \times$. Cells were dispersed by pipetting and then $10 \mu \mathrm{mol} /$ 1 lucigenin and $0.2 \mathrm{mmol} / 1 \mathrm{NADPH}$ were added to the cell suspension. Emitted luminescence was quantified for $12 \mathrm{~s}$ in a luminometer (Berthold, Bad Wildbad, Germany). Results were normalised to the DNA content measured using Hoechst 33258 dye (Sigma-Aldrich Chemie, Buchs, Switzerland).

Western blotting, total RNA preparation and real-time $P C R$ For western blotting, nuclear extracts were separated by SDS-PAGE and blotted on nitrocellulose membranes as described [13]. The proteins were detected using specific antibodies and visualised with IRDye 800 (Rockland, Gilbertsville, PA, USA) as secondary antibodies, and quantified in an imaging system (Odyssey Infrared; Li-COR, Lincoln, NE, USA). Total RNA from insulin-secreting cell lines and pancreatic islets was extracted using phenol/chloroform extractions as described previously [13]. Reverse transcription reactions were per- formed as previously described [23]. Real-time PCR assays were carried out on a real-time PCR detection system (MyiQ Single-Color; Bio-Rad Laboratories, Hercules, CA, USA) using the iQ SYBR Green Supermix (Bio-Rad Laboratories) exactly as previously described by Abderrahmani et al. [13]. Primer sequences of rat/mouse origin for Rab3a, Slp4, Icer and Rplp0 were those published elsewhere [25]. Otherwise primer sequences are described in the electronic supplementary material [ESM] Table 1.

Statistical analyses Experiments including more than two groups were analysed by ANOVA or with the nonparametric equivalent Kruskal-Wallis test.

\section{Results}

Oxidised LDL-cholesterol particles hamper insulin production and insulin secretion, as well as beta cell survival by inducing the activity of Icer We first assessed whether induction of Icer links oxidised LDL to beta cell failure. In vitro oxidisation of LDL-cholesterol particles by copper have been previously shown to generate changes in LDL particles similar to those occurring in endothelial cells, including lipid peroxidation and extensive hydrolysis of phosphatidylcholine [28]. To evaluate the effects of oxidised LDL on beta cells, LDL particles were oxidised by copper as performed in many reports [6, 29, 30]. Our previous study had shown that culture of beta cells for $72 \mathrm{~h}$ with oxidised LDL containing $2 \mathrm{mmol} / \mathrm{l}$ cholesterol (physiological concentration), diminished the insulin level and cell survival [13]. Here, reduction in insulin expression and cell integrity was already visible in cells exposed for $72 \mathrm{~h}$ to 1 and $1.5 \mathrm{mmol} / 1$ cholesterol of oxidised LDL, but the effect was less pronounced than with $2 \mathrm{mmol} / \mathrm{l}$ cholesterol of modified LDL (ESM Fig. 1). As previously shown, $0.5 \mathrm{mmol} / 1$ oxidised LDL was not efficient in triggering harmful effects on the cells (ESM Fig. 1) [13]. The decrease in insulin expression achieved by oxidised LDL occurred at a time point at which cell death was not yet apparent (ESM Fig. 2) [13]. This implies that impaired levels of the hormone are not merely the consequence of a reduced number of cells caused by apoptosis. While native LDL can exert deleterious effects on beta cell secretion and proliferation above $3 \mathrm{mmol} / \mathrm{l}$ (A. Abderrahmani and D. Favre, unpublished observations) [16], the unmodified lipoproteins at $2 \mathrm{mmol} / \mathrm{l}$ cholesterol triggered no effect on beta cell function [13, 14]. For these reasons, we chose this cholesterol concentration to carefully investigate the effects of oxidised LDL. We found a two- to threefold increase in levels of ICER isoforms in MIN6 and INS-1 cells, as well as in isolated rat islets cultured with oxidised LDL 
(Fig. 1a). Two ICER isoforms (ICER and ICER I $\gamma$ ) that result from alternative splicing of CREM mRNA have been described [31]. These two isoforms act as transcriptional repressors whose abundance varies within cell types and species [31]. MIN6 cells produce one ICER isoform, while INS-1E cells contain the two forms of the repressor (Fig. 1b). An increase in the contents of all ICER isoforms by oxidised LDL was confirmed at the protein level by western blotting in the two cell types (Fig. 1b). As anticipated (Fig. 1a, b), neither the protein nor mRNA levels of the repressor were augmented in response to native LDL. ICER is a transcriptional passive repressor, which inhibits the expression of genes that contain a CRE in their promoter region $[24,32]$. This is achieved by competing with CREB transcriptional activators for binding to the CRE sequence $[24,32]$. To assess the activity of ICER in response to oxidised LDL, MIN6 cells were transfected with the luciferase reporter construct driven by two CRE sequences linked upstream to a SV40 promoter (CREluc). While native LDL did not modify luciferase

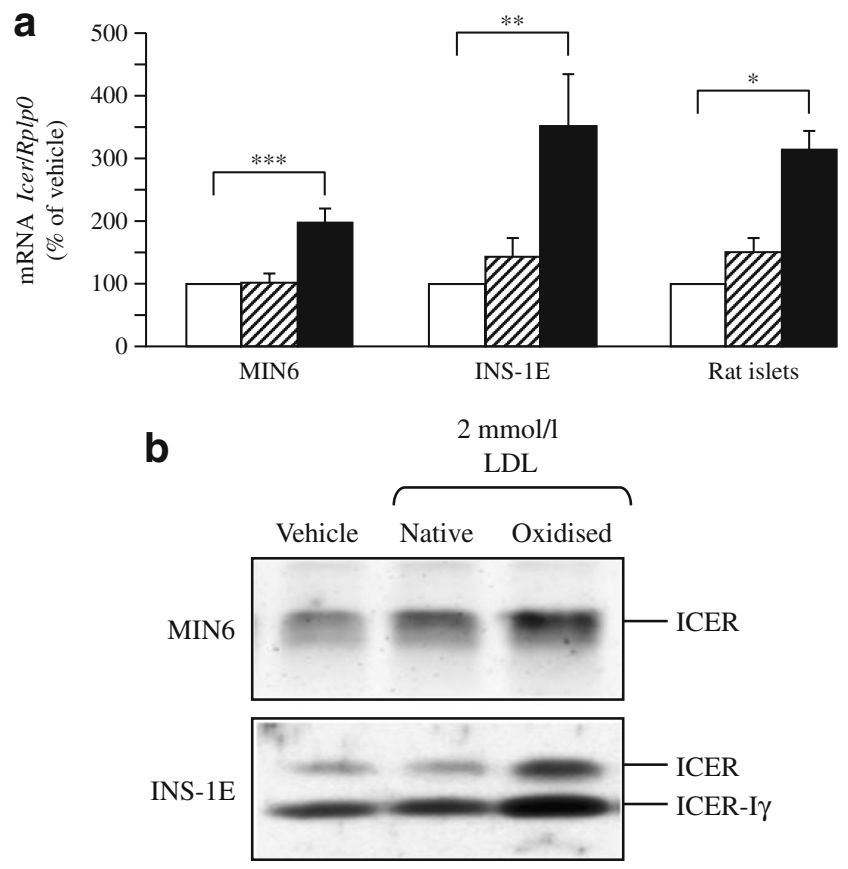

Fig. 1 mRNA and protein levels of ICER in response to oxidised LDL. a The mRNA level of Icer was quantified by quantitative realtime PCR using total RNA from MIN6, INS-1E and isolated rat islet cells cultured for $72 \mathrm{~h}$ with vehicle (white bars), native LDL (hatched bars) or oxidised LDL (black bars). mRNA was normalised against the housekeeping gene, Rplp0, and expression from cells cultured with vehicle was set to $100 \%$. Data are mean \pm SEM of three independent experiments; $* p<0.05, * * p<0.01$ and $* * * p<0.001$. b Quantification of ICER content in response to oxidised LDL. Total protein from cells that were cultured with native or oxidised LDL $2 \mathrm{mmol} / \mathrm{l}$ cholesterol was subjected to western blotting analysis. Blot shows results of a representative experiment (one of three) activity, oxidised LDL treatment strikingly decreased CREluc activity, suggesting that repressor activity of ICER was elevated (ESM Fig. 3). The expression of target genes of ICER was next quantified to confirm the increased ICER activity in response to oxidised LDL. The insulin gene [27], IB1 (also known as MAPK8IP1) [23] and four genes of the secretory machinery, the GTPases Rab3a and Rab27a and their effectors Slp4 and Noc2 [25], are known targets of ICER. In line with the increase in ICER abundance, expression of all these target genes was diminished in cells cultured with oxidised LDL, but not in those cultured with native particles (Fig. 2a-f). To clearly establish whether ICER is responsible for these effects, we blocked expression of the repressor using siRNAs (si-Icer). The efficacy and specificity of the si-Icer in beta cells has already been tested in a former study [25]. The mRNA of $I b 1$ and insulin in cells cultured with oxidised LDL was partially restored upon silencing of Icer (Fig. 2a, b). In contrast, silencing of Icer was able to fully restore the levels of the four genes of the secretory machinery (Fig. 2c-f).

We next investigated the causal role of ICER in beta cell dysfunction and death triggered by oxidised LDL. The decreased expression of $I b I$ caused by oxidised LDL is responsible for sustained induction of the JNK pathway [13]. Activation of this signalling cascade by oxidised LDL leads in isolated rat islets and MIN6 cells to apoptosis through a mechanism involving reduced expression of B-cell CLL/lymphoma 2 [13]. Consistent with the restored mRNA Ibl expression, blockade of ICER protected the cells against apoptosis evoked by oxidised LDL (Fig. 3a). As previously reported [14], we found that oxidised LDL compromise glucose-induced insulin secretion (ESM Fig. 4). Rab3a, Rab27a, Slp4 and Noc2 play major role in the control of insulin exocytosis [25]. This led us to assume that the late steps of insulin exocytosis were impaired in the presence of modified LDL. Exogenously produced hGH has previously been shown to be targeted to secretory granules and to be coreleased with insulin after triggering of exocytosis [33]. As, in contrast to insulin, hGH biosynthesis is not affected by oxidised LDL, secretion of this hormone was used to directly monitor the exocytotic process in cells cultured with the lipoproteins. In addition, the use of hGH as a reporter for exocytosis allows selective assessment of the secretory process in the fraction of cells that are cotransfected with the siRNAs. Potassium chloride $(\mathrm{KCl})$ is a potent insulin secretagogue that triggers exocytosis of insulin-containing vesicles through direct depolarisation of the beta cell membrane [34]. Culture of the cells with oxidised LDL altered secretion elicited by $\mathrm{KCl}$ (Fig. 3b). This result suggests a defect in the distal steps of the secretory process, which could be the consequence of reduced expression of Rab3a, Rab27a, 

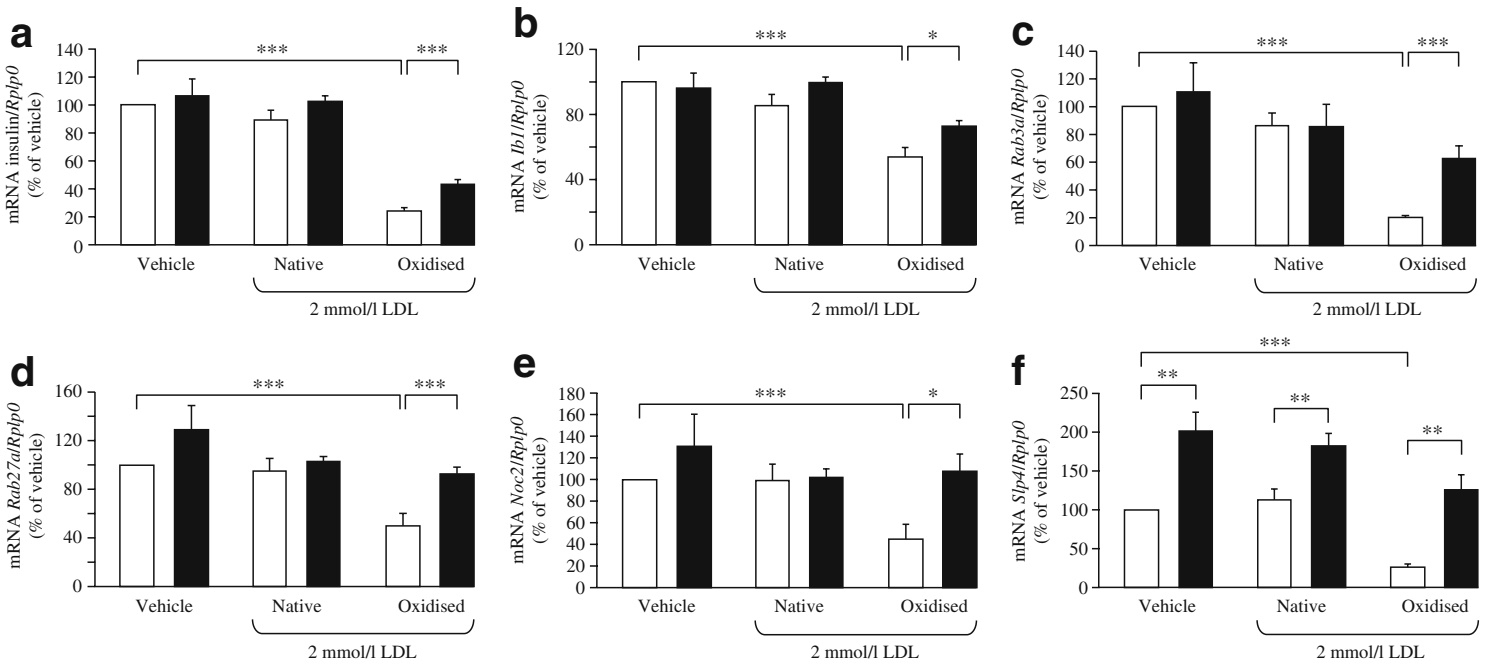

Fig. 2 Expression of ICER target genes in the presence of oxidised LDL. mRNA of (a) insulin, (b) $I b 1$, (c) Rab3a, (d) Rab27a, (e) Noc2 and (f) Slp4 was quantified in MIN6 cells exposed for $72 \mathrm{~h}$ to human native LDL or oxidised LDL containing $2 \mathrm{mmol} / \mathrm{l}$ cholesterol. The cells were transfected with duplexes of control siRNA (si-Gfp)

(white bars) or siRNA directed specifically against ICER (si-Icer, black bars). mRNA levels were normalised against Rplp0 and expression from cells cultured with vehicle were set to $100 \%$. Data are the mean \pm SEM of three independent experiments; ${ }^{*} p<0.05,{ }^{* *} p<$ 0.01 and $* * * p<0.001$

Slp4 and Noc2. Secretion elicited by $\mathrm{KCl}$ was completely restored when expression of Icer was suppressed (Fig. 3b), confirming the direct role of the repressor in perturbation of the late steps of insulin secretion caused by oxidised LDL.

Antioxidant treatment prevents induction of Icer and oxidised LDL-mediated beta cell failure Oxidised LDL are potent inducers of oxidative stress in several cell types $[17,18]$. Oxidative stress is a metabolic process that consists of formation of reactive oxygen species (ROS). In physiological concentrations, endogenous ROS help to maintain homeostasis [35]. However, when ROS accumulate in excess for prolonged periods as observed for all the environmental stressors related to diabetes, they trigger adverse effects [18, 36-39]. Incubation of MIN6 cells with oxidised LDL elicited a twofold increase in superoxide production (Fig. 4a). Similar levels were reached in cells exposed to hydrogen peroxide for $1 \mathrm{~h}$, indicating that oxidised LDL are potent inducers of oxidative stress in insulin-secreting cells (Fig. 4a). We then investigated whether oxidative stress can induce expression of Icer. Treatment with hydrogen peroxide resulted in four-, twoand 1.7-fold induction of the expression of Icer, in MIN6 cells, and isolated islets of rat and humans, respectively (Fig. 4b). To confirm the role of oxidative stress in induction of Icer achieved by oxidised LDL, the cells were co-cultured with the modified lipoproteins and the antioxidant, $N$-acetylcysteine (NAC) at $1 \mathrm{mmol} / \mathrm{l}$. NAC is the acetylated precursor of the amino acid L-cysteine and reduced glutathione. NAC exerts a powerful antioxidant

action by elevating the level of glutathione. Addition of NAC abolished induction of Icer caused by oxidised LDL in MIN6, and in isolated islets of rat and humans (Fig. 4ce). Co-treatment with NAC enabled partial protection of the cells against loss of insulin level (Fig. 5a) and completely restored glucose-induced insulin secretion executed by oxidised LDL (Fig. 5b). Restoration of the secretory capacity was in line with the rise in expression of the genes of the secretory machinery (ESM Fig. 5). Coincubation of the cells with NAC prevented cell death triggered by oxidised LDL in MIN6 and isolated rat islets (Fig. 5c, d). HDL-cholesterol particles antagonise the adverse effects of oxidised LDL in beta cells [13, 15] and display antioxidant properties [40]. Co-culture of MIN6 cells in the presence of HDL prevented the induction of Icer caused by oxidised LDL (Fig. 6), pointing to the repressor as an important link coupling oxidative stress to beta cell failure achieved by the modified LDL.

\section{Discussion}

Evidence of adverse effects of pro-atherogenic oxidised LDL on beta cells $[13,15,16]$ is now growing. Several independent in vitro studies agree in pointing to a deleterious impact of these modified lipoproteins on insulin level, glucose-induced insulin secretion and ultimately cell survival in different insulin-secreting and islet cells $[13,15,16]$. Such harmful effects, which are potentiated by inadequate levels of and/or inactive HDL, 

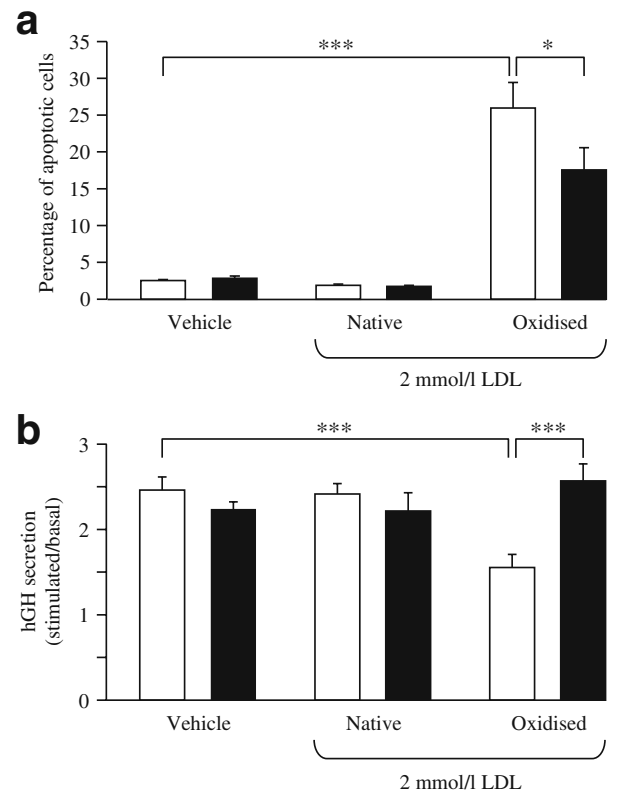

Fig. 3 Effect of Icer silencing on secretion and survival. a MIN6 cells were transfected with a control RNA duplex (si-Gfp) (white bars) or with si-Icer (black bars). Cells were then cultured for $72 \mathrm{~h}$ with native or oxidised LDL $2 \mathrm{mmol} / 1$ cholesterol. The fraction of cells undergoing apoptosis was determined by scoring the percentage of cells with picnotic nuclei. b Measurement of insulin exocytosis. MIN6 cells were transiently transfected with hGH together with the control siRNA (white bars) or si-Icer (black bars), and cultured as above (a). Secretion of hGH was elicited by pre-incubating cells for $30 \mathrm{~min}$ in $\mathrm{KRB}$ containing $2 \mathrm{mmol} / \mathrm{l}$ glucose and then incubating them with $\mathrm{KCl}$ $30 \mathrm{mmol} / \mathrm{l}$. The amount of hGH released into the medium during the incubation period and remaining in the cells was measured by ELISA. The results are expressed as fold increase of stimulated over basal. Data $(\mathbf{a}, \mathbf{b})$ are the mean \pm SEM of three independent experiments; ${ }^{*} p<$ 0.05 and $* * * p<0.001$

are thought to promote and contribute to the progression of diabetes $[13,15]$. Our aim here was to understand the mechanism through which oxidised LDL leads to beta cell dysfunction. ICER is a basic leucine zipper transcriptional factor that negatively regulates expression of numerous genes containing a CRE sequence within their promoter. The lack of an activation domain makes ICER into a passive transcriptional repressor [24]. The inhibitory role of ICER is achieved at certain levels of abundance. Thereafter, the repressor acts by competing with transcriptional activators and preventing their binding to the CRE [24]. Induction of ICER is a physiological process that permits levels of some hormones in endocrine or neuroendocrine cells to return to basal [41]. However, persistent expression of this repressor can occur in response to a deleterious milieu [41]. In this study, we found that abnormal induction of ICER links oxidised LDL to beta cell dysfunction. Selective reduction of ICER contents partially prevented the loss of insulin expression and cell death evoked by oxidised LDL. Loss of specialised beta cell functions caused by the modified lipoproteins preceded cell death. While ICER is responsible for beta cell failure and death, our observations imply that beta cell dysfunction driven by the repressor is established prior to cell death. Variation in islet brain 1 levels is critical for maintaining appropriate insulin content and cell survival $[13,22]$. As observed in our former study [13], the islet brain 1 level was dramatically diminished in the face of oxidised LDL, confirming that loss of islet brain 1 function mediates at least some of the damages to beta cells provoked by the modified lipoprotein. Reduction of islet brain 1 abundance inhibits the insulin level and increases apoptosis by permitting activation of the JNK pathway [22]. While ICER can directly target the gene coding for insulin [42], it could also cause the loss of insulin expression and cell death indirectly by reducing islet brain 1 content and stimulating the JNK pathway. However, restoration of levels of the scaffold protein was incomplete upon silencing of Icer. This coincided with a partial recovery in insulin production and survival. This result could not be attributed to efficacy of silencing, because si-Icer was able to fully restore the mRNA level of the two other ICER target genes, Noc2 and Rab27a. These observations suggest that additional factors that are independent of ICER could have contributed to the decreased abundance of islet brain 1 provoked by the modified particle. However, as observed for chronic hyperglycaemia [25], it is mostly induction of ICER that operates dysregulation of genes controlling insulin secretion, and thereby the defective secretory capacity of beta cells caused by oxidised LDL. We found that silencing of Icer permitted full protection against impairment of stimulated secretory capacity triggered by oxidised LDL, a finding that correlates with fully restored expression of Noc2 and Rab27a.

The major role of ICER in mediating the adverse effects of oxidised LDL led us to seek the mechanism responsible for its induction. Many in vitro studies show that oxidised LDL favour production of ROS and thus oxidative stress in various cell types [17, 18]. Furthermore, elevated levels of oxidised LDL correlate with an increase in certain markers of oxidative stress, such as heat shock protein 70 in patients with newly diagnosed and long-standing diabetes [43]. For these reasons, we investigated the role of oxidative stress in stimulating production of ICER. In this regard, we first found that oxidised LDL evoked production of superoxide in beta cells. Second, culture of cells with hydrogen peroxide elicited an increase in ICER levels. Finally, NAC antioxidant treatment abrogated the induction of ICER caused by oxidised LDL. Consistent with this result, mRNA expression of ICER target genes Rab3a, Rab27a, Slp 4 and Noc2 was restored. This was further accompanied by full recovery of glucose-induced insulin secretion. 

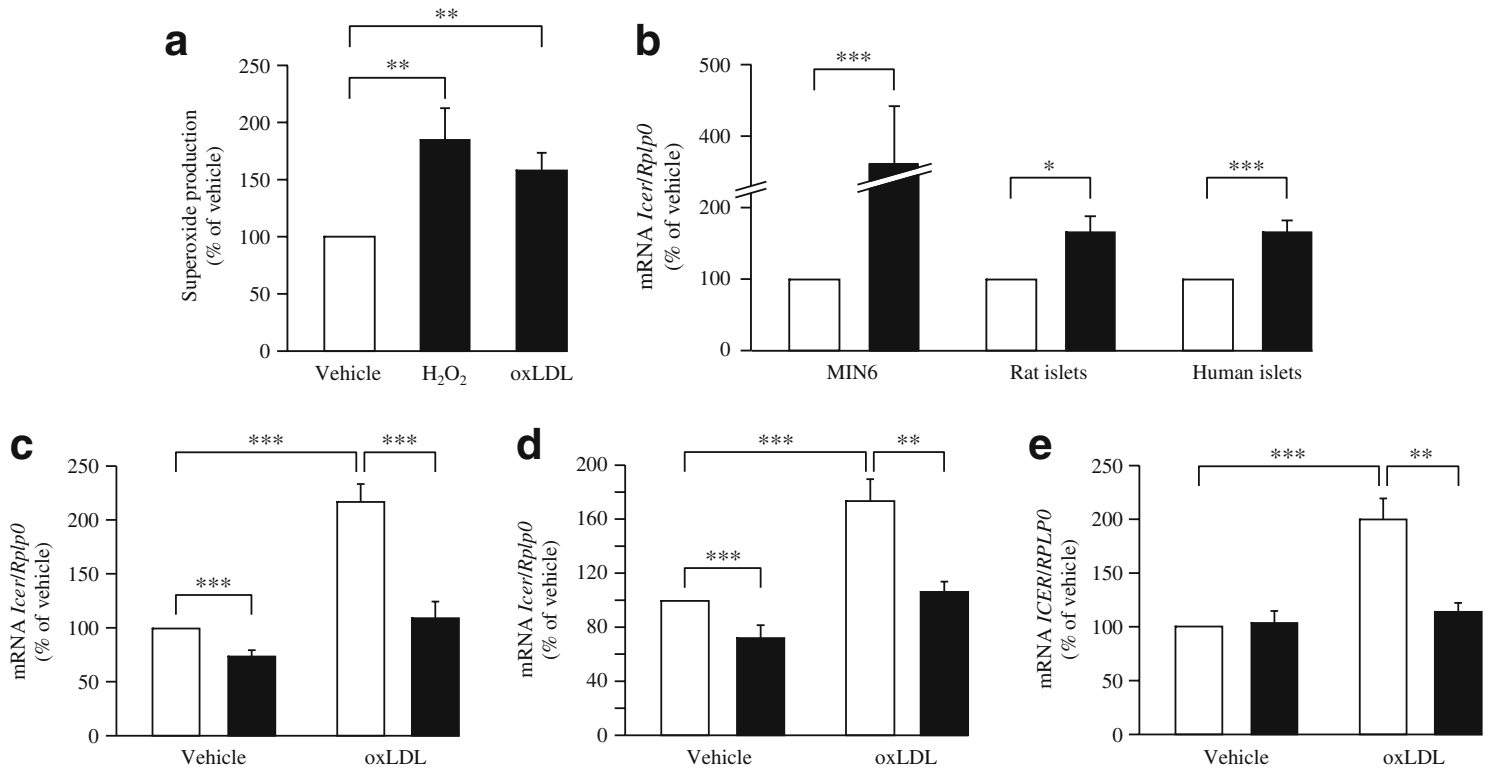

Fig. 4 Role of oxidative stress in the induction of Icer by oxidised LDL. a Production of superoxide in response to oxidised LDL. Extracellular ROS were measured by luminescence. MIN6 cells were cultured for $1 \mathrm{~h}$ with oxidised LDL $2 \mathrm{mmol} / \mathrm{l}$ (oxLDL) or hydrogen peroxide $150 \mu \mathrm{mol} / 1\left(\mathrm{H}_{2} \mathrm{O}_{2}\right)$. Superoxide production in cells cultured with vehicle condition was set to $100 \%$. b Effects of hydrogen peroxide on the expression of Icer. The mRNA level of Icer was quantified by quantitative real-time PCR from MIN6 cells, isolated rat islets cultured for $4 \mathrm{~h}$ and human islets cultured for $0.5 \mathrm{~h}$ with hydrogen peroxide $150 \mu \mathrm{mol} / 1$ (black bars). mRNA levels were normalised against the $\operatorname{Rplp0}$ and expression from cells cultured with vehicle was set to $100 \%$. c-e Effects of the antioxidant NAC on expression of Icer evoked by oxidised LDL. The mRNA level of Icer was quantified by quantitative real-time PCR using total RNA that was prepared from (c) MIN6 cells, and isolated rat (d) and human (e) islets cultured for $4 \mathrm{~h}$ with oxidised LDL $2 \mathrm{mmol} / \mathrm{l}$ cholesterol. The cells were co-incubated with vehicle (white bars) or NAC (black bars) $1 \mathrm{mmol} / 1$ for MIN6 and isolated rat islets (c, d) or $10 \mathrm{mmol} / \mathrm{l}$ for human islets (e). Results were normalised against RPLPO and expression from cells cultured with vehicle was set to $100 \%$. a-e Data are the mean $\pm \mathrm{SEM}$ of three independent experiments; ${ }^{*} p<0.05$, $* * p<0.01$ and $* * * p<0.001$
However, NAC treatment was partially effective in preventing the loss of insulin transcript accomplished by oxidised LDL. This observation leads us to assume that another mechanism, parallel to oxidative stress, accounts for the partial reduction of insulin caused by the modified LDL. Administration of NAC strongly improved survival of MIN6 cells in the presence of oxidised LDL, supporting the notion of a cytoprotective role of the antioxidant

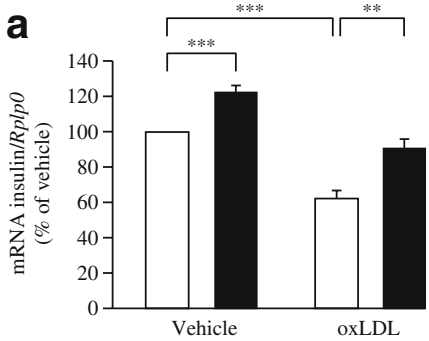

b

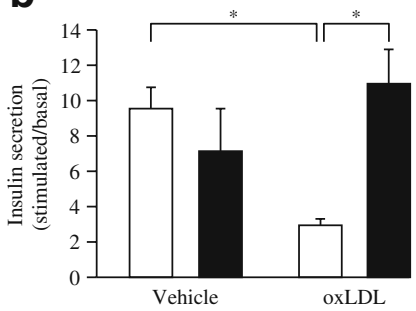

C

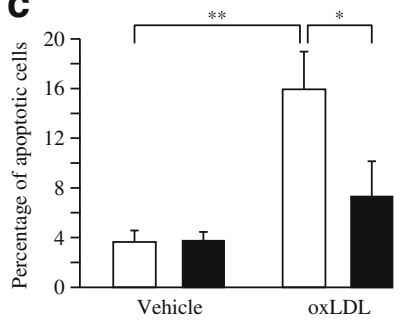

d

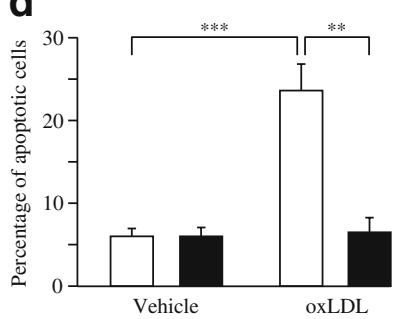

Fig. 5 Counteractive effect of NAC on adverse effects of oxidised LDL on beta cell functions. a Insulin expression in the presence of NAC. MIN6 cells were cultured for $72 \mathrm{~h}$ with oxidised LDL (oxLDL) $2 \mathrm{mmol} / \mathrm{l}$ cholesterol in the presence of vehicle (white bars) or NAC $1 \mathrm{mmol} / \mathrm{l}$ (black bars). The insulin mRNA level was determined by quantitative real-time PCR. mRNA levels were normalised against $R p l p 0$ and the results obtained in cells cultured with vehicle were set to $100 \%$. b Assessment of glucose-induced insulin secretion. MIN6 cells were cultured for $72 \mathrm{~h}$ with oxidised LDL $2 \mathrm{mmol} / \mathrm{l}$ cholesterol plus vehicle (white bars) or NAC $1 \mathrm{mmol} / \mathrm{l}$ (black bars). For measurement of glucose-induced insulin secretion, the cells were pre-incubated for $60 \mathrm{~min}$ in KRB containing $2 \mathrm{mmol} / \mathrm{l}$ glucose (basal) and successively incubated in the same buffer or in KRB containing $20 \mathrm{mmol} / \mathrm{l}$ glucose (stimulated). The amount of insulin release and cellular contents during the incubation period were measured by EIA. Results are expressed as the ratio between the amount of insulin released into the medium under stimulatory and basal conditions over basal condition. $\mathbf{c}, \mathbf{d}$ Cell survival in the presence of NAC. MIN6 cells (c) and dispersed rat islet cells (d) were cultured for $72 \mathrm{~h}$ with oxidised LDL $2 \mathrm{mmol} / 1$ cholesterol plus vehicle (white bars) or NAC $1 \mathrm{mmol} /$ 1 (black bars). The fraction of cells undergoing apoptosis was determined by scoring cells with pycnotic nuclei. a-d Data are expressed as the mean \pm SEM of three independent experiments; $* p<$ $0.05,{ }^{* *} p<0.01$ and ${ }^{* * *} p<0.001$ 


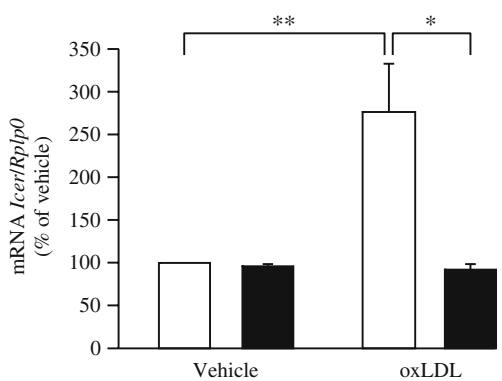

Fig. 6 Effects of HDL on oxidised LDL-induced Icer expression. MIN6 cells were cultured for $4 \mathrm{~h}$ with oxidised LDL (oxLDL) $2 \mathrm{mmol} / \mathrm{l}$ cholesterol in the presence of vehicle (white bars) or $1 \mathrm{mmol} / \mathrm{l} \mathrm{HDL}$-cholesterol (black bars). Icer mRNA was determined by quantitative real-time PCR. mRNA levels were normalised against Rplp 0 and the results obtained in cells cultured with vehicle were set to $100 \%$. Data are the mean \pm SEM of three independent experiments; $* p<0.05$ and $* * p<0.01$

against the deleterious effects of the modified lipoprotein in beta cells. Even though primary beta cells were not examined, the protective effect of NAC was almost complete in isolated islets. Activation of the JNK pathway and decrease of $B c l 2$ expression are partially responsible for apoptosis elicited by oxidised LDL [13]. Generation of oxidative stress could therefore be the leading upstream cause of activation of JNK pathway and decrease of B-cell CLL/lymphoma 2 levels, in a mechanism that could also involve ICER.

HDL particles are potent antioxidants [40] and exert many beneficial effects in beta cells. They not only stimulate beta cell function [15], but also counter loss of beta cell functions and cell survival achieved by oxidised LDL or chronic hyperglycaemia $[13,15,16]$. In line with this cytoprotective role, we found that HDL abolished induction of ICER evoked by oxidised LDL. As observed for oxidised LDL, chronic excess of glucose elicits beta cell dysfunction and death by generating intracellular oxidative stress and elevating ICER levels $[25,44]$. Thus, it is very likely that HDL particles counteract adverse effects provoked by prolonged exposure to glucose by inhibiting oxidative stress and consequently blocking ICER production. However, the plasma concentration of HDL particles and their activity are reduced in patients with diabetes or metabolic syndrome $[7,8]$. For this reason, much is being done to find out effective therapeutic strategies to elevate plasma HDL. It has, however, been suggested that loss of HDL activity in patients with type 2 diabetes might be the consequence of an oxidised LDL-mediated decrease in lecithin-cholesterol acyltransferase activity [45]. Therefore it is possible that oxidised LDL elicit oxidative stress and, consequently, beta cell failure by directly abolishing the protective effects of HDL. In this case, as long as oxidised LDL are present, improvement of HDL levels in patients may not effectively counteract beta cell failure. If this hypothesis is correct, then the use of other alternative antioxidant approaches to counteract oxidative stress in beta cells may be required. Numerous in vitro and in vivo studies have shown the efficacy of certain antioxidants in preventing beta cell failure. For example, administration of the antioxidant NAC alone or in combination with some vitamins ameliorated glucose-induced insulin secretion in Zucker diabetic fatty rats and $d b / d b$ mice $[44,46]$. In contrast, large clinical trials failed to detect an improvement in insulin secretion in patients with type 2 diabetes in response to antioxidant vitamins $[47,48]$. However some findings in favour of preventive antioxidant therapy to combat the decline of beta cell function in diabetes have been reported, in particular, a clinical study originally devised with the primary endpoint efficacy of the antioxidant succinobucol in cardiovascular outcomes in patients with acute coronary disease [19]. Interestingly, daily administration of the antioxidant succinobuccol has been found to reduce occurrence of new-onset diabetes by almost threefold [19]. Succinobuccol is derived from probucol, a bisphenol molecule that preserves beta cells by attenuating oxidative stress [49]. NAC is a potent antioxidant, which is widely used as an antidote for hepatotoxicity caused by acetaminophen overdose. At present, a growing body of data supports many other clinical benefits from use of this antioxidant. These include: prevention of chronic obstructive pulmonary disease exacerbation, attenuation of illness from the influenza virus, treatment of pulmonary fibrosis and treatment of infertility in patients with clomifeneresistant polycystic ovary syndrome [50]. Therefore, antioxidant supplementation in a subset of patients with low HDL levels and elevated oxidised LDL could help to prevent beta cell failure and thereby delay the development of diabetes.

Induction of ICER by oxidative stress may represent the unifying mechanism for beta cell failure provoked by chronic hyperglycaemia, hyperlipidaemia and oxidised LDL. For the future design of effective and potent antioxidant preventive treatment, careful examination of their ability to counteract adverse effects of diabetes stressors in beta cells will be required.

Acknowledgements This work was supported by grants from the Swiss National Foundation (310000-121999, 31003A-127254 and 310030-122586 to A. Abderrahmani, R. Regazzi and G. Waeber, respectively). We were also supported by the Placide Nicod and Octav Botnar Foundations. A. Abderrahmani is supported by the Chair of Excellence from the French National Agency for Research no. ANR-10-CEXC-005-01.

Duality of interest The authors declare that there is no duality of interest associated with this manuscript. 
Open Access This article is distributed under the terms of the Creative Commons Attribution Noncommercial License which permits any noncommercial use, distribution, and reproduction in any medium, provided the original author(s) and source are credited.

\section{References}

1. Donath MY, Ehses JA, Maedler K et al (2005) Mechanisms of $\beta$ cell death in type 2 diabetes. Diabetes 54(Suppl 2):S108-S113

2. Brunham LR, Kruit JK, Verchere CB, Hayden MR (2008) Cholesterol in islet dysfunction and type 2 diabetes. J Clin Invest 118:403-408

3. Hao M, Head WS, Gunawardana SC, Hasty AH, Piston DW (2007) Direct effect of cholesterol on insulin secretion: a novel mechanism for pancreatic beta-cell dysfunction. Diabetes 56:2328-2338

4. Carpentier A, Mittelman SD, Bergman RN, Giacca A, Lewis GF (2000) Prolonged elevation of plasma free fatty acids impairs pancreatic beta-cell function in obese nondiabetic humans but not in individuals with type 2 diabetes. Diabetes 49:399-408

5. Poitout V, Robertson RP (2002) Minireview: secondary beta-cell failure in type 2 diabetes - a convergence of glucotoxicity and lipotoxicity. Endocrinology 143:339-342

6. Okajima F, Kurihara M, Ono C, Nakajima Y et al (2005) Oxidized but not acetylated low-density lipoprotein reduces preproinsulin mRNA expression and secretion of insulin from HIT-T15 cells. Biochim Biophys Acta 1687:173-180

7. Steinberg D, Parthasarathy S, Carew TE, Khoo JC, Witztum JL (1989) Beyond cholesterol. Modifications of low-density lipoprotein that increase its atherogenicity. $\mathrm{N}$ Engl $\mathrm{J}$ Med 320:915-924

8. Ruderman NB, Haudenschild C (1984) Diabetes as an atherogenic factor. Prog Cardiovasc Dis 26:373-412

9. Taskinen MR (2003) Diabetic dyslipidaemia: from basic research to clinical practice. Diabetologia 46:733-749

10. Nakhjavani M, Khalilzadeh O, Khajeali L et al (2010) Serum oxidized-LDL is associated with diabetes duration independent of maintaining optimized levels of LDL-cholesterol. Lipids 45:321327

11. Cullen P, von Eckardstein A, Souris S, Schulte H, Assmann G (1999) Dyslipidaemia and cardiovascular risk in diabetes. Diabetes Obes Metab 1:189-198

12. Rohrer L, Hersberger M, von Eckardstein A (2004) High density lipoproteins in the intersection of diabetes mellitus, inflammation and cardiovascular disease. Curr Opin Lipidol 15:269-278

13. Abderrahmani A, Niederhauser G, Favre D et al (2007) Human high-density lipoprotein particles prevent activation of the JNK pathway induced by human oxidised low-density lipoprotein particles in pancreatic beta cells. Diabetologia 50:1304-1314

14. Brewer HB Jr (2004) High-density lipoproteins: a new potential therapeutic target for the prevention of cardiovascular disease. Arterioscler Thromb Vasc Biol 24:387-391

15. Drew BG, Duffy SJ, Formosa MF et al (2009) High-density lipoprotein modulates glucose metabolism in patients with type 2 diabetes mellitus. Circulation 119:2103-2111

16. Rutti S, Ehses JA, Sibler RA et al (2009) Low- and high-density lipoproteins modulate function, apoptosis, and proliferation of primary human and murine pancreatic beta-cells. Endocrinology $150: 4521-4530$

17. Maziere C, Morliere P, Santus R et al (2004) Inhibition of insulin signaling by oxidized low density lipoprotein. Protective effect of the antioxidant Vitamin E. Atherosclerosis 175:23-30

18. Stocker R, Keaney JF Jr (2004) Role of oxidative modifications in atherosclerosis. Physiol Rev 84:1381-1478
19. Tardif JC, McMurray JJ, Klug E et al (2008) Effects of succinobucol (AGI-1067) after an acute coronary syndrome: a randomised, double-blind, placebo-controlled trial. Lancet 371:1761-1768

20. Kaneto H, Matsuoka TA, Nakatani Y, Kawamori D, Matsuhisa M, Yamasaki Y (2005) Oxidative stress and the JNK pathway in diabetes. Curr Diabetes Rev 1:65-72

21. Kaneto H, Matsuoka TA, Katakami N et al (2007) Oxidative stress and the JNK pathway are involved in the development of type 1 and type 2 diabetes. Curr Mol Med 7:674-686

22. Beeler N, Riederer BM, Waeber G, Abderrahmani A (2009) Role of the JNK-interacting protein 1/islet brain 1 in cell degeneration in Alzheimer disease and diabetes. Brain Res Bull 80:274-281

23. Ferdaoussi M, Abdelli S, Yang JY et al (2008) Exendin-4 protects beta-cells from interleukin-1 beta-induced apoptosis by interfering with the c-Jun NH2-terminal kinase pathway. Diabetes 57:12051215

24. Molina CA, Foulkes NS, Lalli E, Sassone-Corsi P (1993) Inducibility and negative autoregulation of CREM: an alternative promoter directs the expression of ICER, an early response repressor. Cell 75:875-886

25. Abderrahmani A, Cheviet S, Ferdaoussi M, Coppola T, Waeber G, Regazzi R (2006) ICER induced by hyperglycemia represses the expression of genes essential for insulin exocytosis. EMBO J 25:977-986

26. Zhou YP, Marlen K, Palma JF et al (2003) Overexpression of repressive cAMP response element modulators in high glucose and fatty acid-treated rat islets. A common mechanism for glucose toxicity and lipotoxicity? J Biol Chem 278:51316-51323

27. Inada A, Hamamoto Y, Tsuura Y et al (2004) Overexpression of inducible cyclic AMP early repressor inhibits transactivation of genes and cell proliferation in pancreatic beta cells. Mol Cell Biol 24:2831-2841

28. Steinbrecher UP, Parthasarathy S, Leake DS, Witztum JL, Steinberg D (1984) Modification of low density lipoprotein by endothelial cells involves lipid peroxidation and degradation of low density lipoprotein phospholipids. Proc Natl Acad Sci USA 81:3883-3887

29. Cnop M, Hannaert JC, Grupping AY, Pipeleers DG (2002) Low density lipoprotein can cause death of islet beta-cells by its cellular uptake and oxidative modification. Endocrinology 143:3449-3453

30. Scheidegger KJ, Cenni B, Picard D, Delafontaine P (2000) Estradiol decreases IGF-1 and IGF-1 receptor expression in rat aortic smooth muscle cells. Mechanisms for its atheroprotective effects. J Biol Chem 275:38921-38928

31. Laoide BM, Foulkes NS, Schlotter F, Sassone-Corsi P (1993) The functional versatility of CREM is determined by its modular structure. EMBO J 12:1179-1191

32. Thiel G, Lietz M, Hohl M (2004) How mammalian transcriptional repressors work. Eur J Biochem 271:2855-2862

33. Iezzi M, Escher G, Meda P et al (1999) Subcellular distribution and function of Rab3A, B, C, and D isoforms in insulin-secreting cells. Mol Endocrinol 13:202-212

34. Abderrahmani A, Niederhauser G, Plaisance V et al (2004) Complexin I regulates glucose-induced secretion in pancreatic $\beta$-cells. J Cell Sci 117:2239-2247

35. Wolff SP, Dean RT (1987) Glucose autoxidation and protein modification. The potential role of 'autoxidative glycosylation' in diabetes. Biochem J 245:243-250

36. Berliner JA, Territo MC, Sevanian A et al (1990) Minimally modified low density lipoprotein stimulates monocyte endothelial interactions. J Clin Invest 85:1260-1266

37. Henriksen T, Mahoney EM, Steinberg D (1981) Enhanced macrophage degradation of low density lipoprotein previously incubated with cultured endothelial cells: recognition by receptors 
for acetylated low density lipoproteins. Proc Natl Acad Sci USA 78:6499-6503

38. Kajimoto Y, Kaneto H (2004) Role of oxidative stress in pancreatic beta-cell dysfunction. Ann NY Acad Sci 1011:168-176

39. Rabinovitch A, Suarez-Pinzon WL, Strynadka K, Lakey JR, Rajotte RV (1996) Human pancreatic islet beta-cell destruction by cytokines involves oxygen free radicals and aldehyde production. J Clin Endocrinol Metab 81:3197-3202

40. Robbesyn F, Garcia V, Auge N et al (2003) HDL counterbalance the proinflammatory effect of oxidized LDL by inhibiting intracellular reactive oxygen species rise, proteasome activation, and subsequent NF-kappaB activation in smooth muscle cells. FASEB J 17:743-745

41. Abderrahmani A, Plaisance V, Lovis P, Regazzi R (2006) Mechanisms controlling the expression of the components of the exocytotic apparatus under physiological and pathological conditions. Biochem Soc Trans 34:696-700

42. Inada A, Someya Y, Yamada Y et al (1999) The cyclic AMP response element modulator family regulates the insulin gene transcription by interacting with transcription factor IID. J Biol Chem 274:21095-21103

43. Nakhjavani M, Morteza A, Meysamie A et al (2010) Serum heat shock protein 70 and oxidized LDL in patients with type 2 diabetes: does sex matter? Cell Stress Chaperones 2:195-201
44. Robertson RP (2004) Chronic oxidative stress as a central mechanism for glucose toxicity in pancreatic islet beta cells in diabetes. J Biol Chem 279:42351-42354

45. Nakhjavani M, Asgharani F, Khalilzadeh O et al (2010) Oxidized low-density lipoprotein is negatively correlated with lecithincholesterol acyltransferase activity in type 2 diabetes mellitus. Am J Med Sci 2:92-95

46. Kaneto H, Kajimoto Y, Miyagawa J et al (1999) Beneficial effects of antioxidants in diabetes: possible protection of pancreatic betacells against glucose toxicity. Diabetes 48:2398-2406

47. Paolisso G, D'Amore A, Galzerano D et al (1993) Daily vitamin E supplements improve metabolic control but not insulin secretion in elderly type II diabetic patients. Diabetes Care 16:1433-1437

48. Sacco M, Pellegrini F, Roncaglioni MC, Avanzini F, Tognoni G, Nicolucci A (2003) Primary prevention of cardiovascular events with low-dose aspirin and vitamin $\mathrm{E}$ in type 2 diabetic patients: results of the Primary Prevention Project (PPP) trial. Diabetes Care 26:3264-3272

49. Gorogawa S, Kajimoto Y, Umayahara Y et al (2002) Probucol preserves pancreatic beta-cell function through reduction of oxidative stress in type 2 diabetes. Diabetes Res Clin Pract 57:1-10

50. Millea PJ (2009) N-acetylcysteine: multiple clinical applications. Am Fam Physician 80:265-269 